\title{
STABILISASI SISTEM DESKRIPTOR LINIER KONTINU
}

\author{
YULIAN SARI \\ Program Studi Matematika, \\ Pascasarjana Fakultas Matematika dan Ilmu Pengetahuan Alam, Universitas Andalas, \\ Kampus UNAND Limau Manis Padang, Indonesia, \\ yuliansari17@gmail.com
}

\begin{abstract}
Abstrak. Kajian tentang kestabilan sistem deskriptor linier kontinu merupakan topik klasik yang telah dikaji oleh berbagai peneliti. Pada paper ini akan diulas kembali tentang kriteria kestabilan dan stabilisasi sistem deskriptor linier kontinu. Metode dekomposisi standar akan digunakan pada pembahasan selanjutnya. Algoritma memilih kontrol feedback pada masalah stabilisasi sistem deskriptor linier kontinu akan diberikan pada akhir tulisan.

Kata Kunci: Kontrol feedback, metode dekomposisi standar, sistem deskriptor regular, stabilisasi.
\end{abstract}

\section{Pendahuluan}

Diberikan suatu sistem persamaan diferensial orde satu sebagai berikut.

$$
E \dot{\mathbf{x}}(t)=A \mathbf{x}(t)+B \mathbf{u}(t), \quad \mathbf{x}(0)=\mathbf{x}_{0},
$$

di mana $E, A \in \mathcal{M}_{n}(\mathbb{R}), B \in \mathcal{M}_{n, m}(\mathbb{R})$. Pada persamaan di atas, $\mathbf{x}(t) \in \mathbb{R}^{n}$ menyatakan variabel keadaan, $\mathbf{u}(t) \in \mathbb{R}^{m}$ adalah variabel kontrol (input), dan $t \in \mathbb{R}_{+}$ menyatakan waktu. Sistem (1.1) sering disebut sebagai sistem deskriptor linier kontinu [2,3]. Secara ringkas, sistem (1.1) ditulis sebagai $[E, A, B]$. Sistem ini sering dijumpai sebagai model untuk beberapa permasalahan, terutama dalam bidang rekayasa, biologi, dan ekonomi $[1,2,3]$.

Jika matriks $E$ adalah singular, sistem (1.1) mungkin tidak mempunyai solusi. Dalam [1] dinyatakan bahwa sistem (1.1), dengan $\operatorname{rank}(E)<n$, memiliki solusi tunggal jika $\operatorname{det}(\lambda E-A) \neq 0$ untuk suatu $\lambda \in \mathbb{C}$. Untuk selanjutnya, sistem (1.1) dengan $\operatorname{det}(\lambda E-A) \neq 0$ untuk suatu $\lambda \in \mathbb{C}$ disebut sistem deskriptor regular.

Salah satu kriteria untuk kestabilan sistem (1.1) adalah bagian riil dari semua nilai eigen pasangan matriks $(E, A)$ bernilai negatif. Sistem (1.1) dikatakan dapat distabilkan jika terdapat kontrol feedback $\mathbf{u}(t)=K \mathbf{x}(t)+\mathbf{w}(t)$ untuk suatu $K \in$ $\mathcal{M}_{m, n}(\mathbb{R})$ dan $\mathbf{w}(t) \in \mathbb{R}^{m}$ sedemikian sehingga sistem loop tertutup

$$
E \dot{\mathbf{x}}(t)=(A+B K) \mathbf{x}(t)+B \mathbf{w}(t)
$$

adalah stabil $[1,2]$. Dalam hal ini, vektor $\mathbf{u}(t) \in \mathbb{R}^{m}$ dikatakan kontrol yang menstabilkan sistem (1.1). Masalah yang akan dikaji pada paper ini adalah bagaimanakah syarat cukup dan perlu agar sistem (1.1) dapat distabilkan. 


\section{Beberapa Hal Tentang Teori Matriks}

Dalam bagian ini disajikan beberapa hal penting berkenaan dengan teori matriks. Teori tersebut berguna untuk mendapatkan syarat perlu dan cukup bagi stabilisasi sistem deskriptor linier kontinu.

Misalkan $E, A \in \mathcal{M}_{n}(\mathbb{R})$. Skalar $\lambda \in \mathbb{C}$ dikatakan nilai eigen berhingga dari suatu pasangan matriks $(E, A)$ jika $\operatorname{det}(\lambda E-A)=0$. Himpunan semua nilai eigen berhingga dari $(E, A)$ dinotasikan dengan $\sigma_{f}(E, A)$. Suatu vektor $\mathbf{x} \in \mathbb{C}^{n} \backslash\{\mathbf{0}\}$ sedemikian sehingga $(\lambda E-A) \mathbf{x}=\mathbf{0}$ disebut sebagai vektor eigen dari $(E, A)$ yang berkaitan dengan nilai eigen $\lambda$. Jika $E$ singular dan $\mathbf{v} \in \mathbb{C}^{n} \backslash\{\mathbf{0}\}$ sedemikian sehingga $E \mathbf{v}=\mathbf{0}$, maka $\mathbf{v}$ disebut sebagai vektor eigen yang berkaitan dengan nilai eigen $\infty$. Himpunan semua nilai eigen dari $(E, A)$ disebut spektrum dari $(E, A)$, dan dinotasikan dengan $\sigma(E, A)$. Jelas bahwa $\sigma(E, A)=\sigma_{f}(E, A) \cup\{\infty\}$ [3].

Matriks $A \in \mathcal{M}_{n}(\mathbb{R})$ dikatakan nilpoten jika $A^{h}=\mathbf{0}$ untuk suatu bilangan bulat positif $h$ dan $A^{h-1} \neq \mathbf{0}$. Bilangan bulat positif terkecil $h$ sedemikian sehingga $A^{h}=\mathbf{0}$ disebut sebagai indeks nilpotensi dari matriks $A$.

\section{Stabilisasi Sistem Deskriptor Linier Kontinu}

Dalam $[1,2]$ dinyatakan bahwa jika terdapat skalar $\alpha, \beta>0$ sedemikian sehingga jika $\mathbf{u}(t)=\mathbf{0}$ untuk $t>0$, maka $\mathbf{x}(t)$ memenuhi

$$
\|\mathbf{x}(t)\|_{2} \leq \alpha \mathrm{e}^{-\beta t}\|\mathbf{x}(0)\|_{2}, \quad t>0 .
$$

Hal tersebut bermakna bahwa jika sistem (1.1) adalah stabil dan $\mathbf{u}(t)=\mathbf{0}$, maka $\lim _{t \rightarrow \infty} \mathbf{x}(t)=0$. Kestabilan sistem (1.1) dapat dikaji dengan mendekomposisi sistem (1.1) menjadi suatu bentuk yang ekivalen dengan sistem tersebut.

Teorema berikut diperlukan untuk mendapatkan suatu sistem yang ekivalen dengan sistem (1.1).

Teorema 3.1. [2] Pasangan matriks $(E, A)$ dengan $E, A \in \mathcal{M}_{n}(\mathbb{R})$, adalah regular jika dan hanya jika terdapat dua matriks nonsingular $P$ dan $Q$ sehingga

$$
Q E P=\operatorname{diag}\left(I_{n_{1}}, N\right), Q A P=\operatorname{diag}\left(A_{1}, I_{n_{2}}\right),
$$

dimana $n_{1}+n_{2}=n, A_{1} \in \mathcal{M}_{n_{1}}(\mathbb{R}), N \in \mathcal{M}_{n_{2}}(\mathbb{R})$, dan $N$ adalah matriks nilpoten.

Dengan menggunakan Teorema 3.1, maka sistem (1.1) dapat ditulis dalam bentuk yang ekivalen, yaitu

$$
\dot{\mathbf{x}}_{1}=A_{1} \mathbf{x}_{1}+B_{1} \mathbf{u}, \quad \mathbf{x}_{1}(0)=\mathbf{x}_{10}
$$

dan

$$
N \dot{\mathbf{x}}_{2}=\mathbf{x}_{2}+B_{2} \mathbf{u}, \quad \mathbf{x}_{2}(0)=\mathbf{x}_{20} .
$$

Subsistem (3.3) disebut sebagai slow-subsistem dan subsistem (3.4) disebut sebagai fast-subsistem. [2].

Teorema 3.2. $[\mathbf{1 , 2 , 3}]$ Sistem (1.1) adalah stabil jika

$$
\sigma_{f}(E, A) \subset \mathbb{C}_{-},
$$


di mana $\mathbb{C}_{-}=\{s \mid s \in \mathbb{C}, \operatorname{Re}(s)<0\}$.

Bukti. ( $\Longrightarrow$ ) Perhatikan kembali Teorema 3.1, terdapat dua matriks non singular $Q$ dan $P$. Dengan mengasumsikan sistem (1.1) regular, sehingga terpenuhinya standar dekomposisi berikut

$$
Q E P=\left[\begin{array}{cc}
I_{n 1} & 0 \\
0 & N
\end{array}\right] \text { dan } Q A P=\left[\begin{array}{cc}
A_{1} & 0 \\
0 & I_{n 2}
\end{array}\right],
$$

di mana $Q, P \in \mathcal{M}_{n}(\mathbb{R})$ adalah matriks nonsingular, $n_{1}+n_{2}=n, A_{1} \in \mathcal{M}_{n_{1}}(\mathbb{R})$, $N \in \mathcal{M}_{n_{2}}(\mathbb{R})$ adalah matriks nilpoten. Misalkan

$$
\mathbf{x}(t)=P\left[\begin{array}{l}
\mathbf{x}_{1}(t) \\
\mathbf{x}_{2}(t)
\end{array}\right], \quad \mathbf{x}_{0}=P\left[\begin{array}{l}
\mathbf{x}_{10} \\
\mathbf{x}_{20}
\end{array}\right] .
$$

Sistem (1.1) ekivalen terhadap sistem berikut

$$
\dot{\mathbf{x}}_{1}(t)=A_{1} \mathbf{x}_{1}(t), \quad \mathbf{x}_{1}(0)=\mathbf{x}_{10}
$$

dengan solusi sebagai berikut.

$$
\begin{aligned}
\dot{\mathbf{x}}_{1}(t) & =A_{1} \mathbf{x}_{1}(t) \\
\mathrm{e}^{-A_{1} t} \dot{\mathbf{x}}_{1}(t) & =\mathrm{e}^{-A_{1} t} A_{1} \mathbf{x}_{1}(t) \\
-\mathrm{e}^{-A_{1} t} A_{1} \mathbf{x}_{1}(t)+\mathrm{e}^{-A_{1} t} \dot{\mathbf{x}}_{1}(t) & =0 \\
\frac{d}{d t} \mathrm{e}^{-A_{1} t} \mathbf{x}_{1}(t) & =0 \\
\int_{0}^{t} \frac{d}{d t} \mathrm{e}^{-A_{1} t} \mathbf{x}_{1}(t) d t & =0 \\
\left.\mathrm{e}^{-A_{1} t} \mathbf{x}_{1}(t)\right|_{0} ^{t} & =0 \\
\mathrm{e}^{-A_{1} t} \mathbf{x}_{1}(t)-\mathrm{e}^{-A_{1}(0)} \mathbf{x}_{1}(0) & =0 \\
\mathrm{e}^{-A_{1} t} \mathbf{x}_{1}(t) & =\mathbf{x}_{1}(0) \\
\mathbf{x}_{1}(t) & =\mathrm{e}^{A_{1} t} \mathbf{x}_{10}, \quad t>0
\end{aligned}
$$

dan

$$
N \dot{\mathbf{x}}_{2}(t)=\mathbf{x}_{2}(t)
$$

dengan solusi

$$
\mathbf{x}_{2}(t)=0, \quad t>0 .
$$

Misalkan ketidaksamaan (3.1) dipenuhi. Dengan menggunakan persamaan (3.6) dan (3.8) diperoleh

$$
\begin{aligned}
\left\|\left[\begin{array}{l}
\mathbf{x}_{1}(t) \\
\mathbf{x}_{2}(t)
\end{array}\right]\right\|_{2} & =\left\|P^{-1} \mathbf{x}(t)\right\|_{2} \\
\left\|\mathbf{x}_{1}(t)\right\|_{2} & \leq\left\|P^{-1}\right\|_{2}\|\mathbf{x}(t)\|_{2} \\
& =\left\|P^{-1}\right\|_{2} \alpha \mathrm{e}^{-\beta t}\|\mathbf{x}(0)\|_{2}, \quad t>0 .
\end{aligned}
$$

Oleh karena $\mathbf{x}_{1}(t)$ memenuhi (3.9), maka sistem (3.7) stabil, sehingga

$$
\sigma_{f}\left(A_{1}\right) \subset \mathbb{C}_{-} .
$$


$(\Longleftarrow)$ Misalkan $(3.9)$ dipenuhi, akan ditunjukkan bahwa terdapat $\alpha, \beta>0$ sedemikian sehingga

$$
\left\|\mathbf{x}_{1}(t)\right\|_{2} \leq\|P\|_{2}^{-1} \alpha \mathrm{e}^{-\beta t}\left\|\mathbf{x}_{1}(0)\right\|_{2}, \quad t>0 .
$$

Perhatikan bahwa

$$
\begin{aligned}
\left\|\mathbf{x}_{1}(t)\right\|_{2} & =\left\|P\left[\begin{array}{l}
\mathbf{x}_{1}(t) \\
\mathbf{x}_{2}(t)
\end{array}\right]\right\|_{2} \\
& \leq\|P\|_{2}\left\|\left[\begin{array}{l}
\mathbf{x}_{1}(t) \\
\mathbf{x}_{2}(t)
\end{array}\right]\right\|_{2} \\
& =\|P\|_{2}\left\|\mathbf{x}_{1}(t)\right\|_{2} \\
& \leq \alpha \mathrm{e}^{-\beta t}\left\|\mathbf{x}_{1}(0)\right\|_{2} \\
& \leq \alpha \mathrm{e}^{-\beta t}\|\mathbf{x}(0)\|_{2}, \quad t>0 .
\end{aligned}
$$

Ketidaksamaan (3.10) memenuhi ketidaksamaan (3.1).

Adakalanya suatu sistem deskriptor linier kontinu regular (1.1) tidak stabil. Dalam [2] dinyatakan bahwa sistem deskriptor yang tidak stabil dapat distabilkan dengan menggunakan kontrol feedback,

$$
\mathbf{u}(t)=K \mathbf{x}(t)+\mathbf{w}(t),
$$

dimana $K \in \mathcal{M}_{m, n}(\mathbb{R})$ dan $\mathbf{w} \in \mathbb{R}^{m}$. Dengan menggunakan kontrol feedback (3.11), maka sistem (1.1) dapat ditulis menjadi

$$
E \dot{\mathbf{x}}(t)=(A+B K) \mathbf{x}(t)+B \mathbf{w}(t) .
$$

Sistem (3.12) disebut sebagai sistem loop tertutup [1,2].

Berikut ini dikemukakan beberapa hal tentang stabilisasi dari suatu sistem deskriptor linier kontinu.

Teorema 3.3. $[\mathbf{1 , 2}]$ Diberikan sistem deskriptor linier kontinu regular

$$
E \dot{\mathbf{x}}(t)=A \mathbf{x}(t)+B \mathbf{u}(t) .
$$

Sistem (3.13) dapat distabilkan jika dan hanya jika

$$
\operatorname{rank}[s E-A \mid B]=n
$$

untuk setiap $s \in \mathbb{C}_{+}$dimana $\mathbb{C}_{+}=\{s \mid s \in \mathbb{C}, \operatorname{Re}(s)>0\}$.

Bukti. $\Longrightarrow$ Menurut Teorema 3.2, sistem (3.13) dapat distabilkan jika dan hanya jika terdapat $K \in \mathcal{M}_{m, n}(\mathbb{R})$ sedemikian sehingga

$$
\sigma_{f}(E, A) \subset \mathbb{C}_{-} .
$$

Pernyataan tersebut ekivalen dengan

$$
\operatorname{rank}[s E-(A+B K)]=n,
$$


untuk setiap $s \in \mathbb{C}_{+}$. Perhatikan bahwa

$$
\begin{aligned}
\operatorname{rank}[s E-(A+B K)] & =\operatorname{rank}\left([s E-A \mid B]\left[\begin{array}{c}
I \\
-K
\end{array}\right]\right) \\
& \leq \min \left\{\operatorname{rank}[s E-A \mid B], \operatorname{rank}\left[\begin{array}{c}
I \\
-K
\end{array}\right]\right\} \\
& =\operatorname{rank}[s E-A \mid B] .
\end{aligned}
$$

Persamaan (3.16) jelas bahwa $\operatorname{rank}[s E-(A+B K)]=n$.

$\Longleftarrow$ Asumsikan bahwa kondisi (3.14) dipenuhi. Dari Teorema 3.1 mestilah terdapat matriks nonsingular $P$ dan $Q$ sedemikian sehingga sistem (3.13) ekivalen dengan subsistem (3.3) dan (3.4). Perhatikan bahwa

$$
\begin{aligned}
\operatorname{rank}[s E-A \mid B] & =\operatorname{rank}[s Q E P-Q A P \mid Q B] \\
& =n_{2}+\operatorname{rank}\left[s I-A_{1} \mid B_{1}\right] \\
& =n
\end{aligned}
$$

untuk setiap $s \in \mathbb{C}_{+}$. Akibatnya $\operatorname{rank}\left[s I-A_{1} \mid B_{1}\right]=n-n_{2}=n_{1}$ untuk setiap $s \in \mathbb{C}_{+}$. Jelas bahwa slow subsistem dapat distabilkan. Oleh karena itu, pilih $K_{1} \in$ $\mathcal{M}_{m, n_{1}}(\mathbb{R})$ sedemikian sehingga $\sigma_{f}\left(A_{1}+B_{1} K_{1}\right) \subset \mathbb{C}_{-}$. Misalkan $K=\left[K_{1} \mid \mathbf{0}\right] P^{-1} \in$ $\mathcal{M}_{m, n_{1}}(\mathbb{R})$. Akibatnya,

$$
\begin{aligned}
\sigma_{f}(E, A+B K) & =\sigma_{f}(Q E P, Q(A+B K) P) \\
& =\sigma_{f}\left(A_{1}+B_{1} K_{1}\right) .
\end{aligned}
$$

Berikut algoritma memilih matriks $K \in \mathcal{M}_{m, n}(\mathbb{R})$ pada kontrol feedback (3.11) sedemikian sehingga sistem (1.1) dapat distabilkan [2]:

langkah (1) Ubah sistem (1.1) menjadi bentuk dekomposisi standar (3.3) dan (3.4).

langkah (2) Pilih $K_{1} \in \mathcal{M}_{m, n_{1}}(\mathbb{R})$ sedemikian sehingga sistem $\left(A_{1}, B_{1}\right)$ stabil. langkah (3) Dapatkan matriks $K \in \mathcal{M}_{m, n}(\mathbb{R})$ dengan cara sebagai berikut.

$$
K=\left(K_{1} \mid \mathbf{0}\right) P^{-1} \text {. }
$$

\section{Ucapan Terima kasih}

Penulis mengucapkan terima kasih kepada Bapak Muhafzan yang telah memberikan masukan dan saran sehingga paper ini dapat diselesaikan dengan baik. Penulis juga mengucapkan terima kasih kepada Bapak Syafrizal Sy, Bapak Admi Nazra, dan Ibu Lyra Yulianti sehingga paper ini dapat dipublikasikan.

\section{Daftar Pustaka}

[1] Dai, L. 1989. Singular Control Systems. Lecture Notes in Control and Information Sciences. Berlin: Springer.

[2] Duan, G. R. 2010. Analysis and Design of Descriptor Linear Systems. New York: Springer.

[3] Virnik, E. 2008. Stability Analysis of Positive Descriptor Systems, Linier Algebra Appl. 429 (2008) 2640-2659. 